\title{
Galleria mellonella for the Evaluation of Antifungal Efficacy against Medically Important Fungi, a Narrative Review
}

\author{
Sana Jemel ${ }^{1,2,3}$, Jacques Guillot ${ }^{1}$, Kalthoum Kallel ${ }^{2,3}$, Françoise Botterel ${ }^{1}$ and \\ Eric Dannaoui $1,4,5, *$ (D) \\ 1 EA Dynamyc UPEC, EnvA, USC Anses, Faculté de Médecine de Créteil, 94000 Créteil, France; \\ jemelsana.benayed@gmail.com (S.J.); jguillot@vet-alfort.fr (J.G.); francoise.botterel@aphp.fr (F.B.) \\ 2 Université Tunis EL Manar, Faculté de médecine de Tunis, Tunis 1007, Tunisie; kallelkalthoum@gmail.com \\ 3 UR17SP03, centre hospitalo-universitaire La Rabta, Jabbari, Tunis 1007, Tunisie \\ 4 Hôpital Européen Georges Pompidou, APHP, Unité de Parasitologie-Mycologie, Service de Microbiologie, \\ 75015 Paris, France \\ 5 Université René Descartes, Faculté de médecine, 75006 Paris, France \\ * Correspondence: eric.dannaoui@aphp.fr; Tel.: +33-1-56-09-39-48; Fax: +33-1-56-09-24-46
}

Received: 20 February 2020; Accepted: 8 March 2020; Published: 11 March 2020

\begin{abstract}
The treatment of invasive fungal infections remains challenging and the emergence of new fungal pathogens as well as the development of resistance to the main antifungal drugs highlight the need for novel therapeutic strategies. Although in vitro antifungal susceptibility testing has come of age, the proper evaluation of therapeutic efficacy of current or new antifungals is dependent on the use of animal models. Mammalian models, particularly using rodents, are the cornerstone for evaluation of antifungal efficacy, but are limited by increased costs and ethical considerations. To circumvent these limitations, alternative invertebrate models, such as Galleria mellonella, have been developed. Larvae of G. mellonella have been widely used for testing virulence of fungi and more recently have proven useful for evaluation of antifungal efficacy. This model is suitable for infection by different fungal pathogens including yeasts (Candida, Cryptococcus, Trichosporon) and filamentous fungi (Aspergillus, Mucorales). Antifungal efficacy may be easily estimated by fungal burden or mortality rate in infected and treated larvae. The aim of the present review is to summarize the actual data about the use of G. mellonella for testing the in vivo efficacy of licensed antifungal drugs, new drugs, and combination therapies.
\end{abstract}

Keywords: Galleria mellonella; Aspergillus spp.; Candida spp.; antifungal; pharmacokinetics

\section{Introduction}

Animal models are still required for testing antifungal treatments prior to their use in humans. Experimental fungal infections are classically performed in rodents (mice, rats) or rabbits [1]. Despite their high relevance, small mammal models have significant drawbacks. In particular, they require dedicated infrastructures, they are difficult to implement, the durations of experimentation are usually long, and ethical considerations limit their use. For all these reasons, alternative models have been developed.

Several interesting mini-host models such as Drosophila melanogaster, Caenorhabditis elegans, and Galleria mellonella have been used for studying the pathophysiology of different fungal species [2,3] and more recently some antifungal treatments have also been evaluated in these models $[4,5]$. The $G$. mellonella model is particularly interesting because it is inexpensive, easy to use, and does not require specialized infrastructures. Larvae of the insect G. mellonella are small, allowing smooth handling, and 
can survive at $37^{\circ} \mathrm{C}$. The results of experiments are easy to be observed by the melanization of the larvae, decreased mobility, and death [6,7]. The immune system in G. mellonella is characterized by several types of hemocytes, several of which have the ability to neutralize and eliminate pathogens $[8,9]$. In medical mycology, this model has been used mainly for virulence studies but is now also used for antifungal evaluation $[2,10,11]$ (Figure 1).

Evaluation strategy

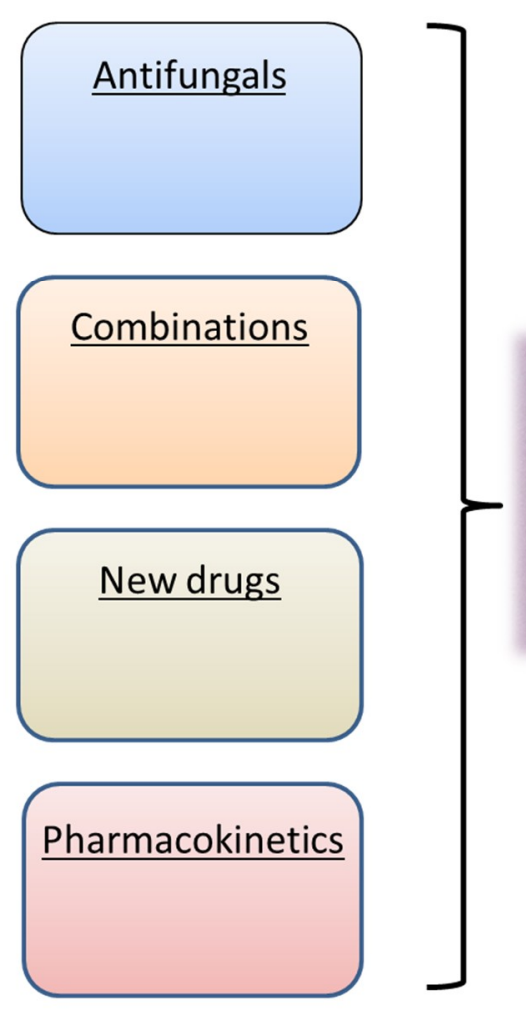

\section{Evaluation parameters}

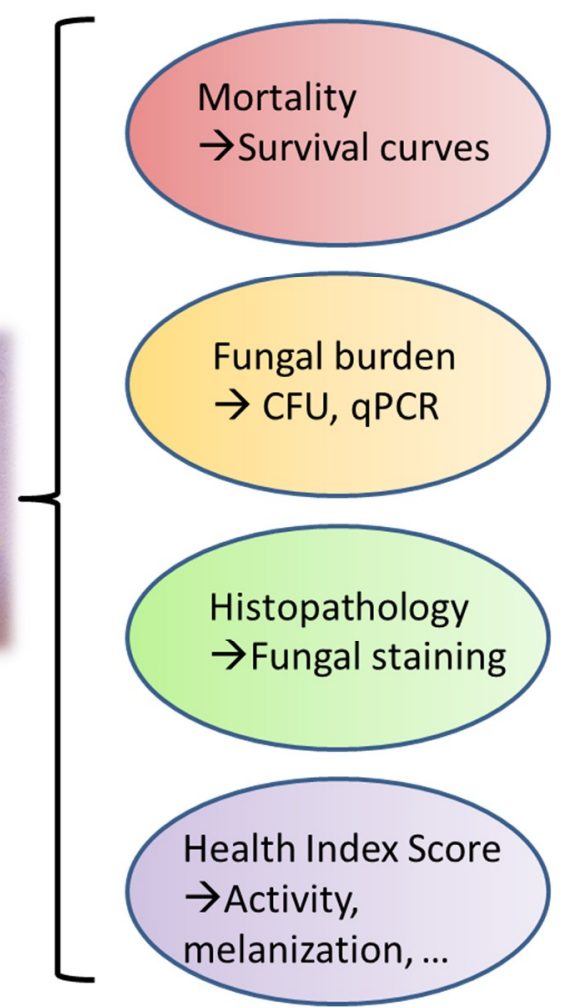

Figure 1. Role of Galleria mellonella for the in vivo evaluation of antifungals.

In this review, after a brief description of the methods and endpoints used for antifungal activity evaluation, we have summarized the actual data about the use of G. mellonella for testing the in vivo efficacy of antifungal drugs.

\section{Methods and Endpoints Used for Evaluation of Antifungal Activity in Galleria mellonella}

G. mellonella larvae are on average $300 \mathrm{mg}$ in weight and $2 \mathrm{~cm}$ in length which makes them easy to manipulate (Figure 2). Inoculations of larvae have essentially been performed by injection of a determined volume in ventral face of the last proleg by insulin or Hamilton syringe to reach the hemocoel [12]. The proleg region before injection has to be cleaned with $70 \%$ ethanol and larvae with dark spots or apparent melanization should be excluded. The number of larvae varies from 10 to 20 per groups and inoculation volume varies from 5 to $20 \mu \mathrm{l}(10 \mu \mathrm{l}$ in most cases) per larva. Preliminary experiments are generally needed to determine the lethal dose that gives $90 \%$ of mortality (LD90).

For treatment, the drugs are generally given by direct injection into the hemocoel. Most studies used a single treatment dose, but multiple dosing is also possible. Nevertheless, multiple injections may be traumatic, favor infection, and result in increased mortality. Among difficulties for treatment administration is the solvent used for drug solubilization. Indeed, many drugs need to be prepared in organic solvents such as dimethylsulfoxide (DMSO). Using DMSO is usually problematic, as this solvent is not so neutral for cell membranes, even at low concentrations, and may be toxic to larvae. This is not a problem for licensed antifungals for which the commercial preparations, which do not 
contain DMSO, are preferably used. Timing of antifungal dosing is an important parameter and should be optimized. Most often, curative treatment in which drugs are given $2-3 \mathrm{~h}$ after infection, have been used. Nevertheless, the efficacy of prophylactic treatment, in which drugs are given before infection can also be evaluated. Treatment with several drugs to assess the efficacy of combinations may also be performed. After inoculation with an LD90, larvae are randomly assigned to the different treatment groups. Two separate groups are given each monotherapy, while the combination group receives the two drugs which are generally given by separate injections. It has to be noticed that administration of some drugs (e.g., caspofungin) to larvae can trigger an immune response (immune priming) and one should be aware of this effect when interpreting results of antifungal efficacy.
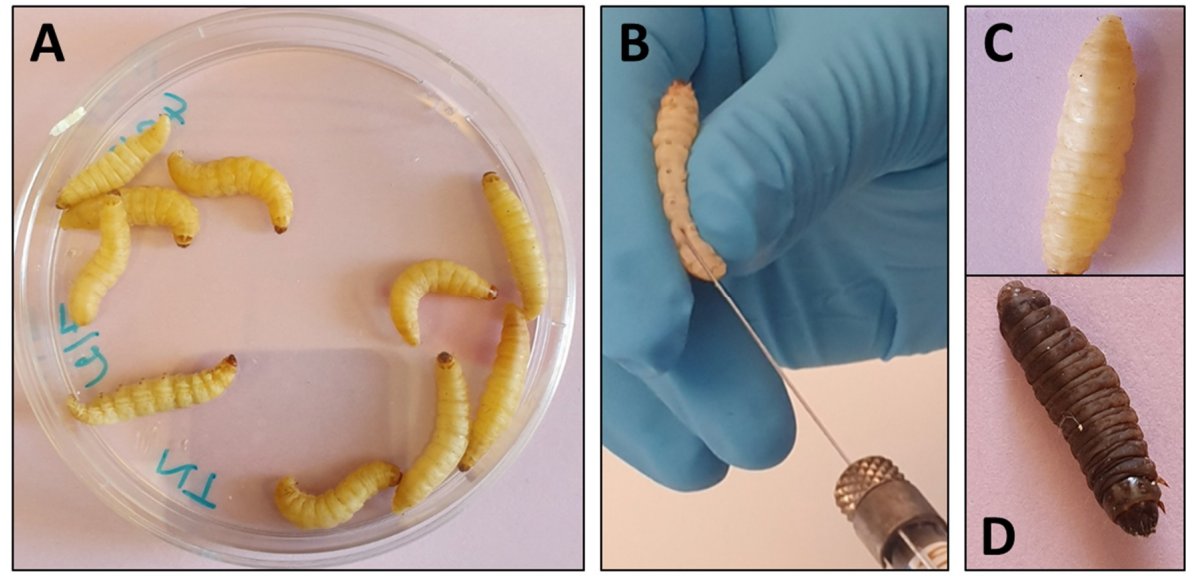

Figure 2. Use of Galleria mellonella larvae for evaluation of antifungal efficacy. (A) Larvae are grouped per ten in Petri dishes. (B) Inoculation and treatment are performed by injection in the ventral face of the last proleg with a Hamilton syringe. (C) Living larva. (D) Dead, melanized, larva.

Different endpoints may be used for evaluation of the efficacy of the antifungal treatment such as mortality, analysis of fungal burden and visualization of histological lesions in infected larvae after treatment (Figure 1). Mortality is recorded at least once daily, and survival data are used to generate Kaplan-Meier curves which can be analyzed by a log-rank test. Estimation of tissue fungal burden can be performed. After homogenization of larval tissues and appropriate dilutions, cultures are performed and Colony Forming Units (CFU) are determined. Use of quantitative PCR may be an alternative to cultures for estimation of fungal burden. Other outcome parameters may be used such as the health scoring system [7] that takes into accounts several endpoints (larval mobility, coccon formation, melanization, survival).

\section{Evaluation of Antifungal Efficacy in Galleria mellonella}

Antifungal efficacy has been evaluated in G. mellonella against a large panel of fungal species including, Candida spp. [13-44], Cryptococcus spp. [32,33,45-51], Aspergillus spp. [13,29,35,52-61], Mucorales [62-64], Madurella mycetomatis [65-67], and other fungal agents [68-70]. The contribution of G. mellonella to the evaluation of antifungal drugs will be detailed in the following paragraphs.

\subsection{Candida spp.}

The genus Candida has been extensively studied in the G. mellonella model especially for the evaluation of virulence and antifungal efficacy [10,71,72]. G. mellonella was used to test the efficacy of different antifungal compounds against Candida yeasts including conventional antifungal drugs [13-23], new drugs [25-27,30-32,34] or non-antifungal compounds in a repurposing perspective [24,28,29,33]. Antifungal combinations against Candida spp. have also been explored in the G. mellonella model [18, 35-44,73]. 


\subsubsection{Conventional Antifungals}

Several studies tested the efficacy of licensed antifungals (polyenes, azoles, echinocandins, and flucytosine) against different species of Candida (Table 1), such as C. albicans [13,14,17,18,21], C. glabrata [13], C. krusei [21], C. tropicalis [15,19], C. parapsilosis species complex [20,23], and uncommon Candida species [22].

Table 1. Evaluation of licensed antifungals efficacy against Candida spp. in G. mellonella.

\begin{tabular}{|c|c|c|c|c|c|}
\hline Species & Antifungal & $\begin{array}{c}\text { Dosage In } \\
\text { Vivo (mg/kg) }\end{array}$ & $\begin{array}{c}\text { In Vitro } \\
\text { Phenotype }\end{array}$ & $\begin{array}{c}\text { In vivo } \\
\text { Efficacy (Gm) }\end{array}$ & Reference \\
\hline C. albicans & FCZ & $3,6,12$ & $S$ & Yes & [13] \\
\hline C. albicans & AMB & 2,4 & $S$ & Yes & [13] \\
\hline C. albicans & CAS & $1,2,4$ & S & Yes & [13] \\
\hline C. albicans & FCZ & $1,4,16$ & $\mathrm{~S}$ & Yes & [18] \\
\hline C. albicans & FCZ & 4 & $\mathrm{R}$ & No & [18] \\
\hline C. albicans & AMB & $0.4,1.6,6.4$ & S & Yes & [18] \\
\hline C. albicans & $5 F C$ & $1.25,5,20$ & $S$ & Yes & [18] \\
\hline C. albicans & AMB & $1,2,4$ & S & Yes & [21] \\
\hline C. albicans & FCZ & $4,12,32,64$ & $S$ & Yes & [21] \\
\hline C. albicans & VRZ & $7.5,10$ & S & Yes & [21] \\
\hline C. albicans & CAS & $1,2,4$ & $\mathrm{~S}$ & Yes & [21] \\
\hline C. glabrata & FCZ & $3,6,12$ & 32 & No & [13] \\
\hline C. glabrata & AMB & 2,4 & $S$ & No at 2, Yes at 4 & [13] \\
\hline C. glabrata & $5 \mathrm{FC}$ & $1,2,4$ & S & $\begin{array}{c}\text { No at } 1, \text { Yes at } 2 \\
\text { and } 4\end{array}$ & [13] \\
\hline C. tropicalis & FCZ & 9 & $S$ & Yes & [15] \\
\hline C. tropicalis & FCZ & 9 & $\mathrm{R}$ & No & [15] \\
\hline C. tropicalis & VRZ & 10 & S & Yes & [15] \\
\hline C. tropicalis & VRZ & 10 & $\mathrm{R}$ & No & [15] \\
\hline C. tropicalis & AMB & 3 & S & Yes & [15] \\
\hline C. tropicalis & AMB & 3 & $\mathrm{R}$ & No & [15] \\
\hline C. tropicalis & ANI & 10 & S & Yes & [15] \\
\hline C. tropicalis & AMB & $1,2,4$ & S & Yes & [19] \\
\hline C. tropicalis & FCZ & ND & S & $\begin{array}{l}\text { Yes high dose, } \\
\text { No low dose }\end{array}$ & [19] \\
\hline C. tropicalis & VRZ & ND & $S$ & $\begin{array}{l}\text { Yes high dose, } \\
\text { No low dose }\end{array}$ & [19] \\
\hline C. tropicalis & CAS & $1,2,4$ & $S$ & Yes & [19] \\
\hline C. krusei & AMB & $1,2,4$ & $\mathrm{~S}$ & $\begin{array}{l}\text { No at } 1 \text { and } 2, \\
\text { Yes at } 4\end{array}$ & [21] \\
\hline C. krusei & FCZ & $4,12,32,64$ & $\mathrm{R}$ & No & [21] \\
\hline C. krusei & VRZ & $7.5,10$ & $\mathrm{~S}$ & $\begin{array}{c}\text { No at 7.5, Yes at } \\
10\end{array}$ & [21] \\
\hline C. krusei & CAS & $1,2,4$ & $S$ & $\begin{array}{c}\text { No at } 1 \text { and } 2, \\
\text { Yes at } 4\end{array}$ & [21] \\
\hline C. orthopsilosis & FCZ & 2,10 & $S$ & Yes & [20] \\
\hline C. orthopsilosis & FCZ & 2,10 & $\mathrm{R}$ & No & [20] \\
\hline C. parapsilosis & FCZ & 14 & S & Yes & [23] \\
\hline C. parapsilosis & FCZ & 14 & $\mathrm{R}$ & No & [23] \\
\hline C. haemulonii & FCZ & 6,12 & $\mathrm{R}$ & No & [22] \\
\hline C. haemulonii & AMB & $2.5,5$ & $\mathrm{R}$ & No & [22] \\
\hline C. haemulonii & CAS & $0,5,1$ & S & Yes & [22] \\
\hline $\begin{array}{l}\text { C. } \\
\text { duobushaemulonii }\end{array}$ & FCZ & 6,12 & $\mathrm{R}$ & No & [22] \\
\hline $\begin{array}{l}\text { C. } \\
\text { duobushaemulonii }\end{array}$ & $\mathrm{AMB}$ & $2.5,5$ & $\mathrm{R}$ & No & [22] \\
\hline $\begin{array}{l}\text { C. } \\
\text { duobushaemulonii }\end{array}$ & CAS & $0,5,1$ & S & Yes & [22] \\
\hline C. tropicalis & FCZ & 6,12 & S & Yes & [22] \\
\hline C. tropicalis & AMB & $2.5,5$ & S & Yes & [22] \\
\hline C. tropicalis & CAS & $0,5,1$ & S & Yes & [22] \\
\hline C. krusei & FCZ & 6,12 & $\mathrm{R}$ & No & [22] \\
\hline C. krusei & AMB & $2.5,5$ & S & Yes & [22] \\
\hline C. krusei & CAS & $0,5,1$ & $\mathrm{~S}$ & Yes & [22] \\
\hline C. lusitaniae & FCZ & 6,12 & $S$ & Yes & [22] \\
\hline C. lusitaniae & AMB & $2.5,5$ & $\mathrm{R}$ & $\begin{array}{c}\text { No at } 2.5 \text {, Yes at } \\
5\end{array}$ & [22] \\
\hline C. lusitaniae & CAS & $0,5,1$ & S & Yes & [22] \\
\hline
\end{tabular}

AMB: amphotericin B; VRZ: voriconazole; FCZ: fluconazole; 5FC: flucytosine; CAS: caspofungin; ANI: anidulafungin; Gm: Galleria mellonella. R: resistant; S: susceptible. 
Although C. albicans is the most frequent species involved in human infections, relatively few studies explored the use of G. mellonella for testing antifungal efficacy against this species. For example, Li et al. showed that fluconazole, amphotericin B, and flucytosine reduced mortality in a dose-dependent manner in larvae infected by C. albicans [18]. Fungal burden data were in concordance with survival results.

C. glabrata is the second cause of invasive candidiasis in USA and Central and Northern Europe [74]. Ames et al. [13] compared the efficacy of fluconazole, amphotericin B and caspofungin for the treatment of infected larvae by a fluconazole-susceptible strain of C. albicans and a strain of C. glabrata that displayed a high MIC of $32 \mu \mathrm{g} / \mathrm{mL}$. Both strains were susceptible to caspofungin and amphotericin B. All dosages of fluconazole promoted survival whereas none protected against C. glabrata infection. Only the highest concentration of caspofungin or amphotericin B decreased the mortality of C. glabrata infected larvae while all doses of these drugs improved survival in C. albicans- infected larvae.

C. tropicalis is another common species evaluated in G. mellonella for the antifungal efficacy $[15,19]$. In a first study, it was shown that all the tested drugs (amphotericin B, caspofungin, fluconazole, and voriconazole) had a protective effect at clinically relevant doses [19]. In another study, several C. tropicalis isolates with different susceptibility profiles to fluconazole and voriconazole were used to infect larvae subsequently treated by fluconazole, voriconazole, amphotericin B, or anidulafungin [15]. Fluconazole improved survival in larvae infected with the fluconazole-susceptible isolate (MIC $0.5 \mu \mathrm{g} / \mathrm{mL}$ ) but not in larvae infected by fluconazole-resistant isolates (MIC $>64 \mu \mathrm{g} / \mathrm{mL}$ ). Overall, there was a good correlation between the in vitro profile and the efficacy in the G. mellonella model. These studies demonstrated that G. mellonella was a good model for testing antifungal efficacy against C. tropicalis.

C. krusei is one of the most frequent Candida species with intrinsic resistance to fluconazole. Efficacy of fluconazole along with other antifungals (amphotericin B, voriconazole, and caspofungin) was evaluated in larvae infected by C. krusei and C. albicans [21]. Fluconazole did not protect larvae infected by C. krusei but improved survival in those infected by C. albicans. All other drugs improved survival during C. krusei infection but with lower efficacy than that observed during C. albicans infection showing that there was a good correlation between the in vitro susceptibility profile and efficacy in the mini model.

Two studies tested the in vivo efficacy of fluconazole against C. parapsilosis species complex isolates [20,23]. In the first study [23], one fluconazole-resistant isolate and one fluconazole- susceptible control isolate of $C$. parapsilosis were used to infect G. mellonella larvae. In terms of survival, fluconazole was active against the susceptible isolate but inactive against the resistant one and concordant results were obtained for the fungal burden. In the other study [20], a clinical isolate of C. orthopsilosis was found to be resistant to fluconazole due to a mutation G458S in Erg11. The in vitro resistance was confirmed in the G. mellonella model based on survival and fungal burden analysis.

Interestingly, G. mellonella was also used to evaluate the therapeutic efficacy in infections due to emerging Candida species. Silva et al. [22] compared the virulence of three species belonging to C. haemulonii complex and the efficacy of antifungal drugs in G. mellonella with non albicans Candida species. All clinical isolates of $C$. haemulonii species complex were resistant to azoles or amphotericin $B$ and susceptible to caspofungin and these in vitro results were correlated with in vivo antifungal efficacy in G. mellonella. Indeed, only caspofungin had a protective effect, based on survival and fungal burden, in C. haemulonii infected larvae when compared with the untreated group. Again, this work showed the correlation between in vitro susceptibility profiles and in vivo efficacy of therapeutic doses in G. mellonella.

Beside the evaluation of antifungal activity against different species, the G. mellonella model can also be used to address unanswered issues. In that perspective, a recent study used the mini-model to explore the in vivo response to antifungals for isolates showing particular in vitro phenotypical characteristics such as trailing growth and paradoxical effect [14]. After selection of several C. albicans isolates exhibiting trailing to azoles and paradoxical effect with echinocandins, infected larvae were treated by voriconazole and caspofungin, respectively. Efficacy of voriconazole was poor in both 
susceptible or trailer isolates and the efficacy of caspofungin was variable among isolates showing in vitro paradoxical effect, precluding solid correlations between trailing or paradoxical effect and in vivo resistance.

Echinocandins are very potent antifungals and represent the first-line therapy for invasive candidiasis. It has been shown that in addition to their direct antifungal activity, echinocandins also possess immunomodulatory effects. Two studies used G. mellonella to demonstrate this effect [16,17]. In the study by Fuchs et al., caspofungin was able to increase survival in C. albicans-infected larvae but the drug also stimulated the innate immune response. This non-specific action protected larvae from other non-fungal microorganisms such as Staphylococcus aureus, which is not susceptible to the drug [17]. Similarly, another study showed that micafungin has an immunomodulatory effect in $G$. mellonella. Micafungin prophylaxis was able to protect larvae from bacterial infection [16]. It was shown that micafungin was able to increase hemocyte density in hemolymph.

\subsubsection{Combinations}

Combination therapy is an interesting approach in difficult-to-treat infections. Antifungal agents may be combined with other antifungals but also with non-antifungal drugs. Several studies have used G. mellonella to demonstrate or to confirm synergistic interactions between drugs (Table 2).

Table 2. Evaluation of antifungal combination efficacy against Candida spp. in G. mellonella.

\begin{tabular}{|c|c|c|c|c|c|}
\hline \multirow[t]{2}{*}{ Species } & \multicolumn{2}{|c|}{ Drugs in Combination } & \multicolumn{2}{|c|}{ Efficacy of the Combination } & \multirow[t]{2}{*}{ Reference } \\
\hline & Partner \#1 & Partner \#2 & In Vitro (SYN) & In Vivo (Gm) & \\
\hline C. albicans & AMB & $5 \mathrm{FC}$ & ND & Yes & [18] \\
\hline C. albicans (Razole) & FCZ & Linezolid & Yes & Yes & [41] \\
\hline C. albicans (Razole) & ITZ & Linezolid & Yes & Yes & [41] \\
\hline C. albicans (Razole) & VRZ & Linezolid & Yes & Yes & [41] \\
\hline C. albicans (Razole) & FCZ & Gentamicin & Yes & Yes & [42] \\
\hline C. albicans (Razole) & FCZ & Minocycline & ND & Yes & [36] \\
\hline C. albicans (Razole) & FCZ & Doxycycline & ND & Yes & [36] \\
\hline C. albicans & CAS & Colistin & Yes & Yes & [75] \\
\hline C. albicans (Razole) & FCZ & Dexamethasone & Yes & Yes & [43] \\
\hline C. albicans (Razole) & FCZ & Licofelone & Yes & Yes & [59] \\
\hline C. albicans (Razole) & FCZ & D-penicillamine & Yes & Yes & [39] \\
\hline C. albicans (Razole) & FCZ & Harmine & Yes & Yes & [37] \\
\hline C. albicans (Razole) & FCZ & Ambroxol & Yes & Yes & [38] \\
\hline C. albicans (Razole) & FCZ & Ribavirin & Yes & Yes & {$[44]$} \\
\hline C. albicans (Razole) & FCZ & $\begin{array}{l}\text { Proton-pump } \\
\text { inhibitors }\end{array}$ & Yes & Yes & [73] \\
\hline C. albicans & FCZ & Hsp90 inhibitors & Yes & Yes & [35] \\
\hline
\end{tabular}

Razole: strain resistant to azole drugs; AMB: amphotericin B; ITZ: itraconazole; VRZ: voriconazole; FCZ: fluconazole; 5FC: flucytosine; CAS: caspofungin; SYN: synergy; Gm: Galleria mellonella.

For instance, the in vivo synergy between amphotericin B and flucytosine was demonstrated against $C$. albicans [18]. While monotherapy by amphotericin B or flucytosine was not effective, the combination of the two drugs significantly improved survival of infected larvae. Combination of amphotericin B with flucytosine is the cornerstone therapy for cryptococcosis and also used for difficult-to-treat invasive candidiasis such as endocarditis, endophthalmitis, and meningitis [76]. This combination may also be of interest for emerging Candida spp. such as C. auris [77] and G. mellonella will be an important tool to confirm the in vitro data.

Combination of antifungals with antibacterial drugs (Table 2) have also been explored [36, $41,42,75]$. For example, the synergy between linezolid, an oxazolidinone synthetic antibacterial, and azoles was evaluated against $C$. albicans [41]. In vitro combination of linezolid with azoles (fluconazole, itraconazole, or voriconazole) showed synergistic interactions against fluconazoleresistant C. albicans. In G. mellonella, only $20 \%$ of infected and untreated larvae survived four days 
after infection. After treatment with combination, survivals were $85 \%, 75 \%$, and $80 \%$ for animals treated by linezolid+fluconazole, linezolid+itraconazole, and linezolid+voriconazole, respectively while it was only $25 \%, 40 \%, 35 \%$, and $35 \%$ after monotherapy by linezolid, fluconazole, itraconazole, and voriconazole, respectively. In the study by Lu et al. it was shown that the combination of gentamicin, an aminoglycoside, with fluconazole was more effective than fluconazole alone in larvae infected with azole-resistant $C$. albicans both in term of survival and fungal burden [42]. These results confirmed the synergistic interactions between fluconazole and gentamicin found in vitro. The in vivo efficacy of tetracycline antibiotics in combination with fluconazole has also been tested. Minocycline+fluconazole and doxycycline+fluconazole combinations in G. mellonella were tested by survival analysis, quantification of $C$. albicans $\mathrm{CFU} / \mathrm{mL}$ and histological analysis [36]. It was concluded that the combinations were synergistic although the level of significance was not reported. In another study, the synergistic effect of colistin (and other antimicrobial peptides) combined with caspofungin was demonstrated in vivo, confirming the in vitro data [75]. There is no doubt that the G. mellonella model will be further useful for the in vivo evaluation of promising combinations between antifungals and antibiotics against emerging fungal pathogens such as C. auris [78].

Several other studies (Table 2) used G. mellonella to demonstrate synergistic interactions between antifungals (mainly fluconazole) and other drugs against $C$. albicans $[35,37-40,43,44,73]$. The partner drugs were anti-inflammatory compounds such as dexamethasone [43] and licofelone [40], Dpenicillamine, a heavy metal chelator [39], harmine, an alkaloid with multiple pharmacological properties [37], ambroxol, a mucolytic drug [38], antivirals such as ribavirin [44], proton-pump inhibitors [73], or Hsp-90 (a molecular chaperone implicated in cellular response to stress) inhibitors [35].

\subsubsection{New Drugs}

Several studies which have focused on the development of new drugs have benefited from the use of G. mellonella as a model for evaluating in vivo efficacy. Several drugs, such as atorvastatin, a cholesterol-lowering agent [24], miltefosine, an anti-leishmanial drug [33], miramistin, an antiseptic [29], and pilocarpine, a muscarinic agonist [28] were evaluated in a repurposing perspective. In other instances, new synthetic compounds or natural products were tested in vivo in the model $[25-27,30$ 32,34]. It must be noticed that in all cases, larvae were infected with C. albicans.

The large amount of currently available data shows that G. mellonella is a very interesting model to evaluate the in vivo efficacy of drugs against Candida spp.

\subsection{Cryptococcus spp.}

The interest and the contribution of G. mellonella for the evaluation of the virulence of Cryptococcus neoformans and its susceptibility to antifungal drugs was demonstrated fifteen years ago [47]. It was shown that G. mellonella is a valuable model due to its thermotolerance and its high susceptibility to infection unlike other invertebrates, like adults of Drosophila melanogaster which are resistant to $C$. neoformans [79]. A summary of studies using G. mellonella as a model for antifungal evaluation against Cryptococcus spp. is shown in Table 3. 
Table 3. Evaluation of antifungal activity for treatment of Cryptococcus infection in Galleria mellonella.

\begin{tabular}{|c|c|c|c|c|}
\hline Species & $\begin{array}{l}\text { Antifungals } \\
(\text { doses }[\mathrm{mg} / \mathrm{kg}])\end{array}$ & Combination & Main Results & Reference \\
\hline C. neoformans & $\begin{array}{l}\text { AMB (1.5) } \\
\text { FCZ (14) } \\
\text { 5-FC (20) }\end{array}$ & Yes & $\begin{array}{l}\text { AMB or FC alone prolonged survival, } \\
\text { FCZ prolonged survival (NS) } \\
\text { AMB+FC more effective then AMB alone }\end{array}$ & [47] \\
\hline $\begin{array}{l}\text { C. neoformans } \\
\text { C. gattii }\end{array}$ & $\begin{array}{c}\operatorname{VRZ}(10,20) \\
\operatorname{AMB}(1,10,20)\end{array}$ & No & $\begin{array}{c}\text { VRZ increased survival and decreased } \\
\text { fungal burden }\end{array}$ & [45] \\
\hline $\begin{array}{l}\text { C. neoformans } \\
\text { C. gattii }\end{array}$ & MFS* & No & $\begin{array}{l}\text { MFS increased survival for C. gattii, and } \\
\text { decreased fungal burden for both species }\end{array}$ & [33] \\
\hline C. neoformans & $\begin{array}{l}\text { AST, A2 } \\
\text { FCZ }\end{array}$ & Yes & $\begin{array}{c}\text { FCZ+AST and FCZ+A2 increased } \\
\text { survival in larvae infected with } \\
\text { FCZ-susceptible isolate }\end{array}$ & [51] \\
\hline C. gattii & $\begin{array}{l}3^{\prime} \text {-hydroxychalcone } \\
(2,80,160) \\
\text { AMB (2) }\end{array}$ & No & $\begin{array}{l}\text { No in vitro-in vivo correlation. 3- } \\
\text { hydroxychalcone fungicidal in vitro but } \\
\text { no efficacy in vivo in terms of survival } \\
\text { and fungal burden }\end{array}$ & [48] \\
\hline $\begin{array}{l}\text { C. gattii } \\
\text { C. neoformans }\end{array}$ & $\begin{array}{l}\text { CHT }(5,10) \\
\text { FCZ }(10)\end{array}$ & No & $\begin{array}{c}\text { CHT increased survival for } C \text {. gattii and } C \text {. } \\
\text { neoformans infected larvae. } \\
\text { Correlation with a murine model }\end{array}$ & [32] \\
\hline $\begin{array}{l}\text { C. neoformans } \\
\text { C. gattii }\end{array}$ & $\begin{array}{l}\text { Compound } 3(5,10) \\
\text { FCZ }(5)\end{array}$ & No & $\begin{array}{l}\text { Compound } 3 \text { increased survival of } \\
\text { infected larvae. Efficacy similar to that of } \\
\text { FCZ }\end{array}$ & [46] \\
\hline C. neoformans & $\begin{array}{l}\operatorname{PED}(6.25 \text { to } 200) \\
\operatorname{AMB}(0.5 \text { to } 4)\end{array}$ & Yes & $\begin{array}{l}\text { AMB or PED increased survival. Better } \\
\text { efficacy of the combination } \\
\text { Good correlation with the murine model }\end{array}$ & [49] \\
\hline C. neoformans & $\begin{array}{l}\text { MK58911 (10 to } \\
\text { 100) } \\
\text { AMB (4) } \\
\text { FCZ (10) }\end{array}$ & Yes & $\begin{array}{l}\text { MK58911 increased survival. No benefit } \\
\text { of MK58911+ AMB and MK58911+FCZ } \\
\text { compared to monotherapies }\end{array}$ & [50] \\
\hline
\end{tabular}

AMB: amphotericin B; FCZ: fluconazole; FC: flucytosine; CHT: 2-(2-(cyclohexylmethylene)hydrazinyl)-4-phenylthiazole; compound 3: 2-[2-(cyclohexylmethylene)hydrazinyl)]-4-)4-methoxyphenyl) thiazole; PED: pedalitine; MFS: miltefosine (free miltefosine $(10$ to $40 \mathrm{mg} / \mathrm{kg}$ ) or miltefosine-loaded alginate nanoparticles $(100 \mathrm{or} 200 \mathrm{mg} / \mathrm{kg})$ ); AST: astemizole; A2: astemizole analogue \#2 (1H-Benzimidazole-2-amine,1-[2-(4-methoxyphenyl)ethyl]-N-[1[2-(4-methoxyphenyl)ethyl]-4-piperidinyl]; NS: Not Significant.

In what is probably the first study of antifungal efficacy in G. mellonella, Mylonakis et al. [47] used the conventional antifungal agents for the treatment of Cryptococcus infection. The administration of amphotericin B or flucytosine was effective in reducing mortality compared to untreated controls. Fluconazole seemed also to be effective, although statistically significance was not reached. It was also shown that the combination of amphotericin B with flucytosine significantly decreased the mortality of infected larvae compared to amphotericin B alone.

Among other licensed antifungals, voriconazole was more recently tested for efficacy against $C$. neoformans and C. gattii infection in G. mellonella [45]. Voriconazole treatment significantly increased survival and decreased fungal burden in infected larvae by both species.

Drug repurposing is currently a widely explored strategy for treatment optimization of cryptococcosis. In that perspective, several compounds such as miltefosine and astemizole, have been tested in G. mellonella for their efficacy against cryptococcosis $[33,51]$. The anti-leishmanial miltefosine, which is also known to possess antifungal activity, was evaluated for the treatment of cryptococcosis. Treatment of $G$. mellonella larvae with miltefosine embedded in alginate nanoparticles reduced mortality and fungal burden in C. gattii-infected larvae [33]. Similarly, astemizole, an antihistaminic drug, as well as one of its analogues were tested in combination with fluconazole [51]. The combination was fungicidal in vitro and significantly increased survival of G. mellonella larvae infected by a fluconazole-susceptible $C$. neoformans isolate.

The potential use of G. mellonella for evaluation of treatment efficacy has also been highlighted in several studies that focused on the development of new molecules with antifungal activities against Cryptococcus spp. [32,46,48-50]. 
Among these studies, Sa et al. [32] evaluated a phenylthiazole derivative (CHT) for the treatment of cryptococcosis and candidiasis in animal models (G. mellonella and a murine model). CHT treatment significantly prolonged survival in C. albicans, C. gattii or C. neoformans-infected larvae and the results were confirmed in a murine model. In another study from the same group [46], the effect of a closely related thiazole derivative (named compound 3) was evaluated for the treatment of $C$. neoformans or $C$. gattii-infected larvae. Treatment with compound 3 resulted in increased survival of infected larvae with an efficacy similar to that of fluconazole.

Sometimes, in vitro activity is not translated to in vivo efficacy in G. mellonella. For example, Palanco et al. [48] tested the efficacy of 3 -hydroxychalcone. Chalcones, which are abundant in plants, have numerous pharmacological activities including antifungal action [80]. The efficacy of this compound was evaluated on groups of larvae infected by one isolate of C. gattii (collected from a psittacine bird) or the strain C. gattii ATCC 56990 (collected from a human). In vitro, 3'hydroxychalone was fungicidal against $C$. gattii both in planktonic and biofilm form but did not decrease the mortality or the fungal burden of infected larvae. This lack of correlation between in vitro activity and in vivo efficacy could possibly be explained by the high hydrophobicity of the compound responsible for a limited distribution in tissues [48].

Other natural substances, such as pedalitin, a compound isolated from a plant, were tested against $C$. neoformans both in vitro and in vivo by using G. mellonella larvae [49]. The combination of pedalitin with amphotericin B was synergistic in vitro. By evaluating mortality, fungal burden, and histopathology, the authors showed that the combination was also effective in vivo in G. mellonella, and that there was a good correlation with the results obtained in the murine model.

Beside plants, animals are also a source of natural compounds with antimicrobial activity. In this context, an antimicrobial peptide analogue isolated from the wasp venom was tested for its anticryptococcal activity [50]. In this study the peptide was active in vitro against C. neoformans, had low toxicity toward mammalians cells, and increased survival in a G. mellonella model of cryptococcosis. The combination of this peptide with either amphotericin B or fluconazole was not more effective than monotherapies.

To conclude, G. mellonella is a suitable model for Cryptococcus infection and could be used for evaluation of antifungal treatments in cryptococcosis. It is interesting to note that very different drugs, including licensed antifungals, new synthetic molecules, or natural compounds, may be evaluated in the G. mellonella model.

\subsection{Trichosporon spp.}

Trichosporon yeasts are responsible for superficial infections but may also behave as opportunistic agents of invasive infections mainly in patients with hematological malignancies [81]. The incidence of fungemia caused by Trichosporon spp. is increasing in patients with hematological malignancies and neutropenia and traditional antifungal drugs are not very efficient against Trichosporon spp. [82]. In a recent study, G. mellonella was evaluated as an animal model of Trichosporon spp. infection [68]. The authors compared the susceptibility of Trichosporon strains to three antifungals drugs in vitro and in vivo in two animal models (mice and G. mellonella). Immunocompromised mice and G. mellonella larvae were infected by different strains of T. asahii $(n=3)$, T. asteroids $(n=3)$, or T. inkin $(n=1)$ and treated with amphotericin B or azoles. Fluconazole was able to improve the survival in both animal models against the three Trichosporon species. In contrast, voriconazole was more effective in the $G$. mellonella model, possibly due to the rapid metabolism of this drug in mice. Amphotericin B was not able to reduce mortality in any cases in infected larvae but only in mice infected with T. asahii strains.

Overall, it can be concluded that the G. mellonella model could be useful for the evaluation of antifungal treatments against Trichosporon spp. 


\subsection{Aspergillus spp.}

The treatment of G. mellonella infected with Aspergillus spp. has been evaluated in several studies (Table 4 ) in order to assess intrinsic resistance in specific species $[55,56,83]$, acquired azole resistance in A. fumigatus [53,54], combinations [35,59], and efficacy of non-antifungal drugs [29,57,58,60,61].

Table 4. Evaluation of antifungal treatment against Aspergillus spp. in Galleria mellonella.

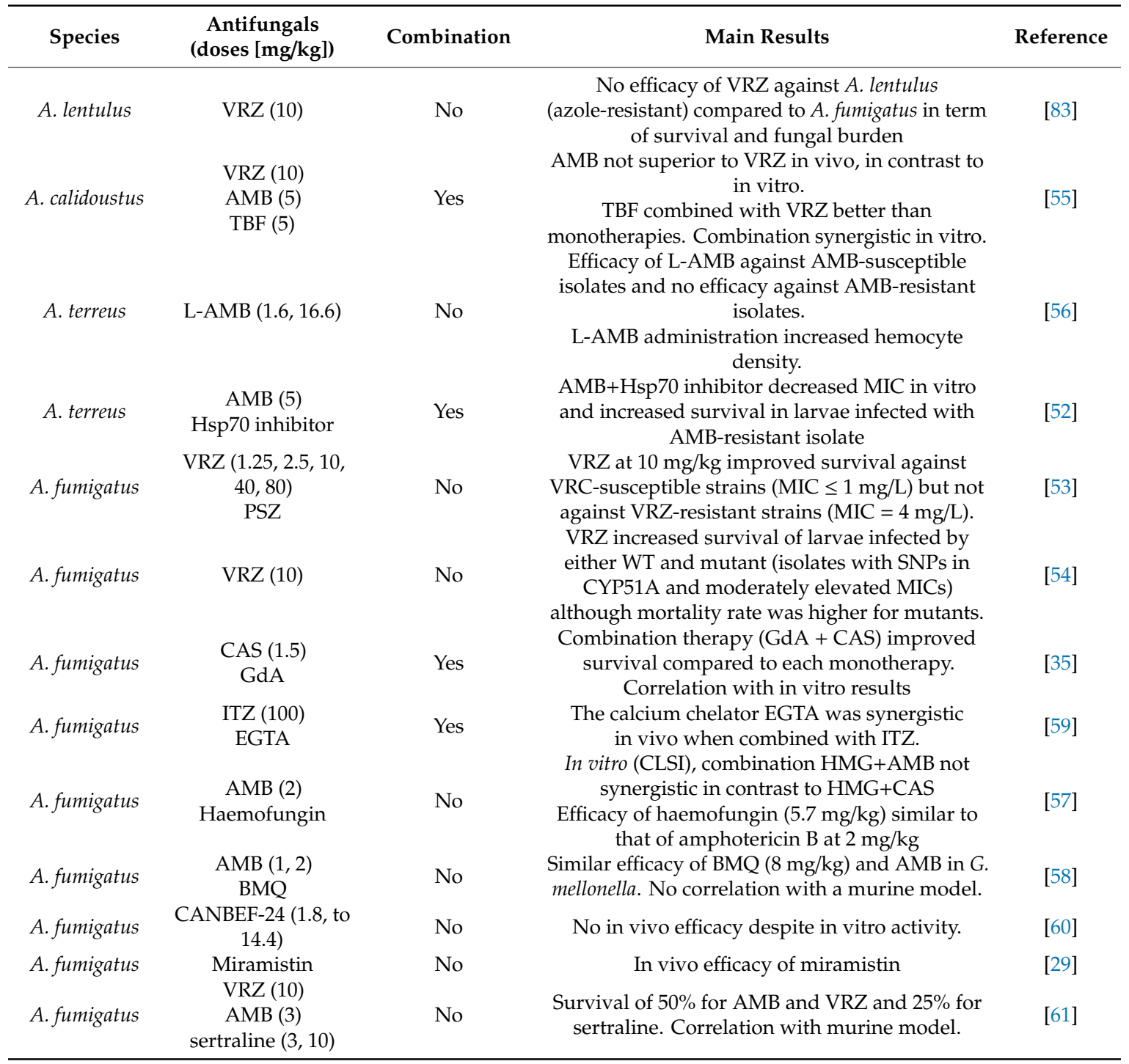

AMB: amphotericin B, VRZ: voriconazole, TBF: terbinafine, CAS: caspofungin, BMQ: bromoquinol, CANBEF-24:

4-chloro-6-arylamino-7-nitro-benzofurazane, GdA: geldanamycin, Gm: Galleria mellonella.

Susceptibility to azoles in cryptic Aspergillus species differs. Aspergillus lentulus, a cryptic species of the A. fumigatus complex (Aspergillus section Fumigati) is less susceptible to voriconazole [84]. Alcazar-Fuoli et al. [83] compared the efficacy of voriconazole on larvae infected with A. fumigatus sensu stricto or with $A$. lentulus. When A. fumigatus was used, $100 \%$ of infected larvae died four days after infection. However, only $80 \%$ of larvae died by day 10 after infection by $A$. lentulus. Treatment with voriconazole resulted in a significant decrease in mortality in larvae infected with $A$. fumigatus compared to untreated controls but not in larvae infected by A. lentulus. Species other than A. fumigatus are emerging and are characterized by a decreased susceptibility to azoles. Glampedakis et al. [55] evaluated different antifungals alone or in combination against $A$. calidoustus both in vitro and in vivo in the G. mellonella model. Although amphotericin B showed a better in vitro activity, it was not 
more active than voriconazole in vivo. Voriconazole combined with terbinafine also showed potential benefit. Susceptibility of Aspergillus terreus to amphotericin B has been evaluated in vitro and in vivo by Maurer et al. [56] by testing susceptible and resistant isolates. Treatment of infected larvae with liposomal-amphotericin B reduced mortality only in larvae infected with the susceptible isolates, demonstrating a good correlation between the in vitro results and the in vivo efficacy in G. mellonella. The model was subsequently used to demonstrate that Hsp70 proteins play an important role in the response of $A$. terreus to amphotericin B [52]. Against amphotericin B resistant strains of $A$. terreus, the combination of amphotericin B and an Hsp70 inhibitor increase survival of larvae compared to amphotericin B alone.

Beside intrinsic resistance, acquired resistance in $A$. fumigatus has become a major problem. Indeed, the last decades have been marked by the emergence of azole-resistant strains of $A$. fumigatus linked to long-term antifungal treatment in patients and fungicide use in the environment [85]. Forestiero et al. [53] tested the efficacy of different dosages of voriconazole and posaconazole on larvae infected by a wild type of A. fumigatus sensu stricto or different isolates with Cyp51A mutations such as G54W or TR/L98H conferring high MICs to posaconazole and/or voriconazole. For larvae infected with azole susceptible strains of $A$. fumigatus (voriconazole $\mathrm{MIC} \leq 1 \mathrm{mg} / \mathrm{L}$ ) and treated with voriconazole, the median survival time was 2 to 3 days versus 7 days in untreated larvae. In contrast, in larvae infected with resistant strains (voriconazole MIC of $4 \mathrm{mg} / \mathrm{L}$ ), survival was not statistically different between treated larvae and untreated controls. In another study, Aspergillus fumigatus isolates with single nucleotide polymorphism (SNP) in Cyp51A and low level of resistance (higher azole MICs but not categorized as resistant based on the current clinical breakpoints) were evaluated in vivo to test if the SNPs were associated with a poorer treatment response. Voriconazole treatment improved survival of larvae infected with a wild-type isolate (40\% survival). Isolates with Cyp51A SNPs also responded to voriconazole to a certain extent but showed a $0 \%$ survival [54].

Up to now, few studies have tested combination treatment of aspergillosis in the G. mellonella model. In one study, combination of geldanamycin, an inhibitor of Hsp 90, with caspofungin was tested in vitro and in vivo against $A$. fumigatus. While caspofungin or geldanamycin alone did not increase survival of larvae inoculated with a lethal dose, the combination of the two drugs significantly protected larvae from death [35]. In the same way it was shown that the combination of itraconazole with EGTA (ethylene glycol tetra-acetic acid), a calcium chelator, was synergistic [59]. Larvae inoculated by a lethal dose of $A$. fumigatus had a survival of $60 \%$ when treated with itraconazole alone, and $87 \%$ when itraconazole was combined with EGTA.

G. mellonella has also been used as an in vivo model for the evaluation of antifungal efficacy of new drugs $[57,58,60]$ or in the context of repurposing $[29,61]$. By screening large chemical libraries, several drugs with promising antifungal activity were identified and further tested in animal models, including G. mellonella [57,58,60]. Bromoquinol, a quinoline, showed efficacy similar to that of the amphotericin B used as a positive control [58]. Nevertheless, the compound showed lower efficacy in a murine model of pulmonary aspergillosis. While amphotericin B was effective compared to controls, bromoquinol did not significantly improve survival of infected mice. Another compound with activity at the cell wall level, called haemafungin, was tested in G. mellonella for its antifungal efficacy [57]. In larvae inoculated with a lethal dose of $A$. fumigatus, haemofungin had a similar efficacy to amphotericin B. A new class of compounds based on a 4-chloro-6-arylamino-7-nitro-benzofurazane molecular structure (CANBEFs) has been identified as potential antifungals [60]. Although one of the compounds (CANBEF-24) showed promising in vitro activity, it was not effective in vivo. Sertraline, a selective serotonin reuptake inhibitor used as antidepressant also has antifungal activities and it has been used recently as an adjunctive therapy in cryptococcal meningitis [86]. Trevino-Rangel et al. [61] compared the efficacy of sertraline for the treatment of invasive aspergillosis in G. mellonella and BALB/C male mice to the efficacy of amphotericin B and voriconazole. Outcome parameters were survival in G. mellonella and fungal burden in mice. Results showed a survival of $>50 \%$ after treatment by voriconazole or amphotericin B and $25 \%$ after treatment by sertraline. In accordance with the results 
obtained in the G. mellonella model, there was a significant reduction in the pulmonary fungal burden in infected mice treated by sertraline. Miramistin, a topical antiseptic, has been tested in vivo and showed efficacy in larvae infected with A. fumigatus [29].

G. mellonella is a suitable host for the development of Aspergillus spp. infection and a valuable alternative to mammalian models for testing the in vivo efficacy of antifungals against aspergillosis.

\subsection{Mucorales}

Mucorales are ubiquitous fungi that are responsible for difficult-to-treat fungal infections in diabetic and immunocompromised individuals [87-89]. Recent years have been marked by a significant increase in mucormycoses worldwide [88,90]. Growth at elevated temperatures is known to be an important virulence factor in several fungal pathogens including Mucorales [91]. Kaerger et al. [91] used G. mellonella to compare the virulence of five thermotolerant Mucorales species: Rhizopus arrhizus, $R$. microsporus, $R$. homothallicus, $R$. caespitosus, and R. schipperae. Maurer et al. [64] showed variability in the virulence of Mucorales as a function of temperature and Rhizopus-infected larvae died more quickly when they were incubated at $37^{\circ} \mathrm{C}$ then at $30^{\circ} \mathrm{C}$.

Although several authors compared the virulence of Mucorales in G. mellonella, only three studies used this model to evaluate antifungal activity (Table 5). Maurer et al. [64] used G. mellonella to test the efficacy of liposomal amphotericin B, posaconazole, isavuconazole, and nystatin-intralipid, an antifungal formulation that has proven to be effective against invasive aspergillosis and invasive candidiasis in a murine model [92]. Antifungals were tested against six Mucorales species, Lichtheimia corymbifera, L. ramosa, R. arrhizus, R. microsporus, Mucor circinelloides, and Rhizomucor pusillus, and the efficacy was compared to in vitro susceptibility tests [64]. Nystatin-intralipid showed the better efficacy against all the species except $R$. arrhizus. Particularly, survival was improved by $60 \%$ and $30 \%$ in nystatin-intralipid treated larvae infected by L. corymbifera and L. ramosa, respectively. These results correlated with the high in vitro activity against Lichtheimia spp. Liposomal amphotericin B, which exhibited the better in vitro activity but showed a low in vivo efficacy except against L. corymbifera. Isavuconazole was not effective except in $M$. circinelloides infected larvae. The pharmacokinetics of isavuconazole, nystatin-intralipid, posaconazole and liposomal amphotericin B was also determined by bioassay in hemolymph at different time points after injection. The concentration of isavuconazole was below the MIC value at $6 \mathrm{~h}$ post injection and reached undetectable levels at $16 \mathrm{~h}$. This could partly explain its limited efficacy. It has also to be noted that esterases are necessary to transform the pro-drug to active isavuconazole. Although esterase activity has been reported in G. mellonella [93] it is not yet known if such esterase activity is able to produce the active drug [64].

Table 5. Evaluation of antifungal treatment against Mucorales in Galleria mellonella.

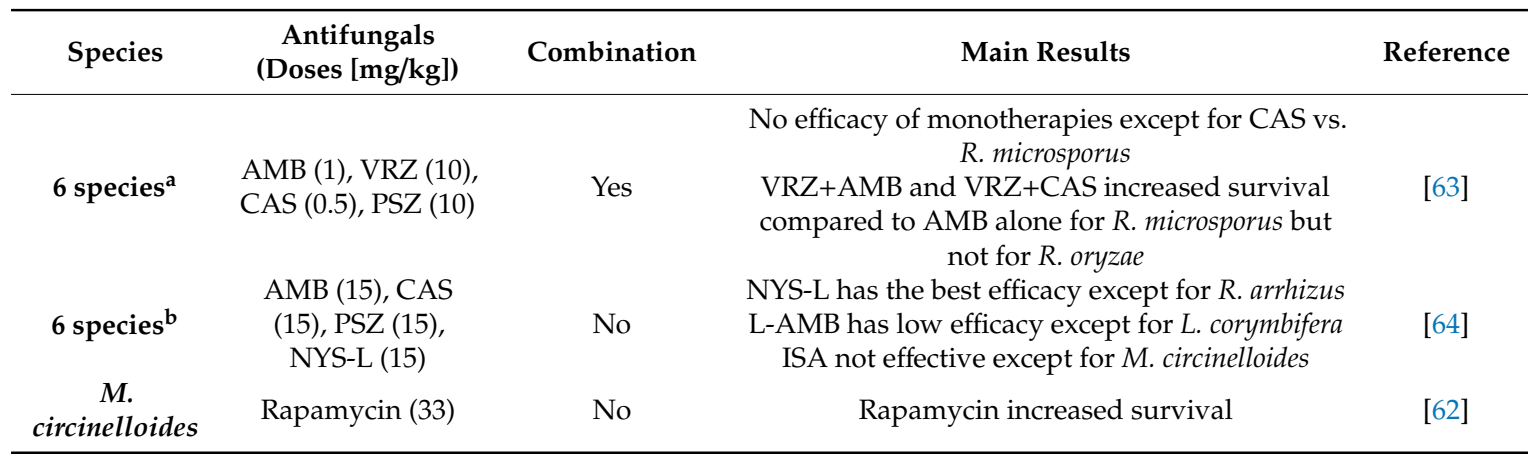

${ }^{a}$ R. microsporus, R. oryzae, S. racemosum, Lichtheimia corymbifera, L. blaskesleeana, L. ramosa. ${ }^{b}$ R. arrhizus, R. microsporus, L. corymbifera, L. ramosa, M. circinelloides, Rh. Pusillus. AMB: amphotericin B; VRZ: voriconazole; CAS: caspofungin; PSZ: posaconazole; NYS-L: nystatin intralipid; L-AMB: liposomal amphotericin B; ISA: isavuconazole. 
Macedo et al. [63] evaluated the efficacy of monotherapy based on therapeutic doses of voriconazole, amphotericin B, caspofungin, and posaconazole for the treatment of larvae infected by R. microsporus or R. arrhizus. Combinations of voriconazole with amphotericin B, caspofungin or posaconazole were also tested by using the lowest antifungal doses that gave hyphae alterations in vitro. Monotherapies did not improve survival of infected larvae except for caspofungin in $R$. arrhizus-infected larvae. Combination of voriconazole with amphotericin B, and voriconazole with caspofungin (despite the reduction of doses of drugs in association) improved the median survival in $R$. microsporus-infected larvae but not in $R$. arrhizus-infected larvae compared to monotherapy. Non-antifungal drugs have also been tested against Mucorales in G. mellonella. For example, rapamycin [62] improved survival by $50 \%$ in $M$. circinelloides-infected larvae.

Although G. mellonella was successfully used to study virulence of Mucorales, more studies are necessary to confirm its usefulness for in vivo evaluation of antifungal treatments.

\subsection{Madurella Mycetomatis}

Eumycetoma are tropical infections due to different fungal species including Madurella mycetomatis. For these infections, there is a limited efficacy of antifungal treatment probably related to the ability of the causative fungi to form grains in infected tissues. Inside the grains, hyphae are protected by a barrier that reduces the action of the antifungal. Because eumycetomas are rare diseases, clinical trials are difficult to perform, and animal models may be of great value for the evaluation of new therapeutic strategies. By comparing histological sections of G. mellonella larvae infected with M. mycetomatis to those of patients and mice, it was demonstrated that grains produced in the larvae resembled those formed in mammalian hosts [94].

The interest of testing the efficacy of antifungals in vivo and more precisely in G. mellonella was highlighted by Kloezen et al. [66]. The authors used a prophylactic (2-h before infection) or a curative (4-h after infection when grains are already formed) treatment to compare the efficacy of the antifungals. They showed that only amphotericin B and terbinafine increased the survival of $M$. mycetomatis-infected larvae whether the protocol was prophylactic or curative. In contrast, azoles did not improve survival. Antifungal combinations were also tested in the same model [65]. Combination of itraconazole with terbinafine was not beneficial, while combination of amphotericin B with either itraconazole or terbinafine decreased survival compared to amphotericin B alone and was therefore antagonistic.

G. mellonella has also been used to test new drugs against M. mycetomatis [67]. After the in vitro screening of 800 molecules, the 10 most potent compounds were tested in vivo in G. mellonella. Several of these compounds showed activity in term of prolonged survival and reduced fungal burden. In particular, a fenarimol analogue, a non-azole Cyp51 inhibitor, showed promising results. Based on these results, several other fenarimol analogues were also tested in G. mellonella model [67].

Overall, several studies have demonstrated that G. mellonella is a suitable model for M. mycetomatis infection with the formation of typical fungal grains in larvae tissue. Moreover, the model seems to be valuable for assessing antifungal efficacy and screening of new molecules potentially active against this difficult-to-treat infection.

\section{Pharmacokinetics of Antifungals in G. mellonella}

The purpose of in vivo experimentation in animal models is essentially the ability to extrapolate the results to human. For this, the pharmacokinetics of antifungals in the animal models used for evaluating antifungal efficacy must be known. The main parameters are the maximum concentration $\left(C_{\max }\right)$, the area under the curve (AUC), and the half-life $\left(\mathrm{T}_{1 / 2}\right)$. In G. mellonella, several studies evaluated the pharmacokinetics of different drugs including ketoconazole, fluconazole, voriconazole, posaconazole, isavuconazole, amphotericin B, nystatin intra-lipid, and terbinafine [53,64,66,95].

Astvad et al. [95] described the pharmacokinetics of fluconazole in G. mellonella hemolymph and tried to determine a humanized dose. The pharmacokinetics of fluconazole showed a linear increase in $\mathrm{C}_{\text {max }}$ and $\mathrm{AUC}_{0-24}$ with the dose. Despite the lack of kidneys, the clearance of the drug in larvae 
was much greater than in humans and the $\mathrm{T}_{1 / 2}$ was about one third of the human value. Overall, the authors found that a dose of $20 \mathrm{mg} / \mathrm{kg}$ of larval tissues would result in a similar exposure to that obtained in humans with a standard dose of fluconazole.

In another study, the pharmacokinetic parameters of voriconazole and posaconazole were determined in non-infected G. mellonella larvae [53]. $\mathrm{AUC}_{0-24}$ of voriconazole after a single dose of 10 $\mathrm{mg} / \mathrm{kg}$ was in the same range as the value observed in human subjects receiving a dose of $8 \mathrm{mg} / \mathrm{kg} / \mathrm{day}$. Similarly, for posaconazole, exposure $\left(\mathrm{AUC}_{0-24}\right)$ was similar in $\mathrm{G}$. mellonella treated by a single injection of $10 \mathrm{mg} / \mathrm{kg}$ and in humans treated by $800 \mathrm{mg} /$ day.

Maurer et al. [64] determined the pharmacokinetics of amphotericin B, isavuconazole, posaconazole, and nystatin intra-lipid after a $15 \mathrm{mg} / \mathrm{kg}$ single dose administration in G. mellonella larvae. They showed that the polyenes were more stable in the hemolymph than azoles and that they exhibited higher $T_{1 / 2}$ and AUC values. The hemolymph concentration of posaconazole and isavuconazole reached an undetectable level at $22 \mathrm{~h}$ and $16 \mathrm{~h}$ after administration, respectively.

In another study, pharmacokinetic characteristics of four azoles (ketoconazole, itraconazole, voriconazole, and posaconazole), amphotericin B, and terbinafine were determined [66]. For amphotericin B given at $1 \mathrm{mg} / \mathrm{kg}, \mathrm{C}_{\max }$ was comparable in G. mellonella and in humans. For azoles, all given at $5.7 \mathrm{mg} / \mathrm{kg}$, different results were obtained: compared to humans, AUC in G. mellonella was lower for ketoconazole and itraconazole, similar for posaconazole, and higher for voriconazole.

Overall, the available studies showed that antifungal drugs are distributed and eliminated in G. mellonella larvae and that it is possible, at least for some antifungal drugs, to use doses that allow exposure similar to that observed in humans. Most of the pharmacokinetic data were obtained in non-infected larvae. Therefore, further studies are warranted to explore possible alterations of pharmacokinetic parameters in infected animals.

\section{Conclusions and Perspectives}

Although G. mellonella was primarily used to study virulence, it is now widely used for testing drugs' efficacy against different fungal species. In many instances, a good correlation with in vitro results and mammalian models has been obtained. Therefore, G. mellonella represents an alternative to mammalian models as a screening tool for antifungal evaluation. The main advantages are the rapidity and low costs compared to the standard mammalian models.

Further studies are needed to refine the reproducibility and standardization of the models developed in G. mellonella. More fungal species must be tested and pharmacokinetic data, particularly in infected larvae, need to be further evaluated.

Author Contributions: Conceptualization, S.J. and E.D.; methodology, S.J. and E.D.; writing-original draft preparation, S.J. and E.D.; writing-review and editing, S.J., J.G., K.K., F.B., and E.D. All authors have read and agreed to the published version of the manuscript.

Funding: This research received no external funding.

Conflicts of Interest: Over the past 5 years, ED received research grants from MSD and Gilead; travel grants from Gilead, MSD, Pfizer, and Astellas; speaker's fee from Gilead, MSD and Astellas. Other authors have no conflict of interest.

\section{References}

1. Hohl, T.M. Overview of vertebrate animal models of fungal infection. J. Immunol. Methods 2014, 410, 100-112. [CrossRef] [PubMed]

2. Arvanitis, M.; Glavis-Bloom, J.; Mylonakis, E. Invertebrate models of fungal infection. Biochim. Biophys. Acta 2013, 1832, 1378-1383. [CrossRef]

3. Chamilos, G.; Lionakis, M.S.; Lewis, R.E.; Kontoyiannis, D.P. Role of mini-host models in the study of medically important fungi. Lancet Infect. Dis. 2007, 7, 42-55. [CrossRef] 
4. Canteri de Souza, P.; Custodio Caloni, C.; Wilson, D.; Sergio Almeida, R. An invertebrate host to study fungal infections, mycotoxins and antifungal drugs: Tenebrio molitor. J. Fungi (Basel) 2018, 4, 125. [CrossRef] [PubMed]

5. Pukkila-Worley, R.; Holson, E.; Wagner, F.; Mylonakis, E. Antifungal drug discovery through the study of invertebrate model hosts. Curr. Med. Chem. 2009, 16, 1588-1595. [CrossRef] [PubMed]

6. Andrea, A.; Krogfelt, K.A.; Jenssen, H. Methods and challenges of using the Greater Wax moth (Galleria mellonella) as a model organism in antimicrobial compound discovery. Microorganisms 2019, 7, 85. [CrossRef] [PubMed]

7. Tsai, C.J.; Loh, J.M.; Proft, T. Galleria mellonella infection models for the study of bacterial diseases and for antimicrobial drug testing. Virulence 2016, 7, 214-229. [CrossRef]

8. Ribeiro, C.; Brehelin, M. Insect haemocytes: What type of cell is that? J. Insect Physiol. 2006, 52, 417-429. [CrossRef]

9. Wojda, I. Immunity of the greater wax moth Galleria mellonella. Insect Sci. 2017, 24, 342-357. [CrossRef]

10. Kavanagh, K.; Sheehan, G. The use of Galleria mellonella larvae to identify novel antimicrobial agents against fungal species of medical interest. J. Fungi (Basel) 2018, 4, 113. [CrossRef]

11. Lionakis, M.S. Drosophila and Galleria insect model hosts: New tools for the study of fungal virulence, pharmacology and immunology. Virulence 2011, 2, 521-527. [CrossRef] [PubMed]

12. Champion, O.L.; Titball, R.W.; Bates, S. Standardization of G. mellonella larvae to provide reliable and reproducible results in the study of fungal pathogens. J. Fungi (Basel) 2018, 4, 108. [CrossRef] [PubMed]

13. Ames, L.; Duxbury, S.; Pawlowska, B.; Ho, H.L.; Haynes, K.; Bates, S. Galleria mellonella as a host model to study Candida glabrata virulence and antifungal efficacy. Virulence 2017, 8, 1909-1917. [CrossRef] [PubMed]

14. Binder, U.; Aigner, M.; Risslegger, B.; Hortnagl, C.; Lass-Florl, C.; Lackner, M. Minimal inhibitory concentration (MIC)-phenomena in Candida albicans and their impact on the diagnosis of antifungal resistance. J. Fungi (Basel) 2019, 5, 83. [CrossRef]

15. Forastiero, A.; Mesa-Arango, A.C.; Alastruey-Izquierdo, A.; Alcazar-Fuoli, L.; Bernal-Martinez, L.; Pelaez, T.; Lopez, J.F.; Grimalt, J.O.; Gomez-Lopez, A.; Cuesta, I.; et al. Candida tropicalis antifungal cross-resistance is related to different azole target (Erg11p) modifications. Antimicrob. Agents Chemother. 2013, 57, 4769-4781. [CrossRef]

16. Fuchs, B.B.; Li, Y.; Li, D.; Johnston, T.; Hendricks, G.; Li, G.; Rajamuthiah, R.; Mylonakis, E. Micafungin elicits an immunomodulatory effect in Galleria mellonella and mice. Mycopathologia 2016, 181, 17-25. [CrossRef]

17. Kelly, J.; Kavanagh, K. Caspofungin primes the immune response of the larvae of Galleria mellonella and induces a non-specific antimicrobial response. J. Med. Microbiol. 2011, 60, 189-196. [CrossRef]

18. Li, D.D.; Deng, L.; Hu, G.H.; Zhao, L.X.; Hu, D.D.; Jiang, Y.Y.; Wang, Y. Using Galleria mellonella-Candida albicans infection model to evaluate antifungal agents. Biol. Pharm. Bull. 2013, 36, 1482-1487. [CrossRef]

19. Mesa-Arango, A.C.; Forastiero, A.; Bernal-Martinez, L.; Cuenca-Estrella, M.; Mellado, E.; Zaragoza, O. The non-mammalian host Galleria mellonella can be used to study the virulence of the fungal pathogen Candida tropicalis and the efficacy of antifungal drugs during infection by this pathogenic yeast. Med. Mycol. 2013, 51, 461-472. [CrossRef]

20. Morio, F.; Lombardi, L.; Binder, U.; Loge, C.; Robert, E.; Graessle, D.; Bodin, M.; Lass-Florl, C.; Butler, G.; Le Pape, P. Precise genome editing using a CRISPR-Cas9 method highlights the role of CoERG11 amino acid substitutions in azole resistance in Candida orthopsilosis. J. Antimicrob. Chemother. 2019, 74, 2230-2238. [CrossRef]

21. Scorzoni, L.; de Lucas, M.P.; Mesa-Arango, A.C.; Fusco-Almeida, A.M.; Lozano, E.; Cuenca-Estrella, M.; Mendes-Giannini, M.J.; Zaragoza, O. Antifungal efficacy during Candida krusei infection in non-conventional models correlates with the yeast in vitro susceptibility profile. PLoS ONE 2013, 8, e60047. [CrossRef] [PubMed]

22. Silva, L.N.; Campos-Silva, R.; Ramos, L.S.; Trentin, D.S.; Macedo, A.J.; Branquinha, M.H.; Santos, A.L.S. Virulence of Candida haemulonii complex in Galleria mellonella and efficacy of classical antifungal drugs: A comparative study with other clinically relevant non-albicans Candida species. Fems Yeast Res. 2018, 18, foy082. [CrossRef] [PubMed]

23. Souza, A.C.; Fuchs, B.B.; Pinhati, H.M.; Siqueira, R.A.; Hagen, F.; Meis, J.F.; Mylonakis, E.; Colombo, A.L. Candida parapsilosis resistance to fluconazole: Molecular mechanisms and in vivo impact in infected Galleria mellonella larvae. Antimicrob. Agents Chemother. 2015, 59, 6581-6587. [CrossRef] [PubMed] 
24. Ajdidi, A.; Sheehan, G.; Abu Elteen, K.; Kavanagh, K. Assessment of the in vitro and in vivo activity of atorvastatin against Candida albicans. J. Med. Microbiol. 2019, 68, 1497-1506. [CrossRef] [PubMed]

25. Browne, N.; Hackenberg, F.; Streciwilk, W.; Tacke, M.; Kavanagh, K. Assessment of in vivo antimicrobial activity of the carbene silver(I) acetate derivative SBC3 using Galleria mellonella larvae. Biometals Int. J. Role Met. Ions Biol. Biochem. Med. 2014, 27, 745-752. [CrossRef] [PubMed]

26. Cruz, L.I.B.; Lopes, L.F.F.; de Camargo Ribeiro, F.; de Sa, N.P.; Lino, C.I.; Tharmalingam, N.; de Oliveira, R.B.; Rosa, C.A.; Mylonakis, E.; Fuchs, B.B.; et al. Anti-Candida albicans activity of thiazolylhydrazone derivatives in invertebrate and murine models. J. Fungi (Basel) 2018, 4, 134. [CrossRef]

27. Favre-Godal, Q.; Dorsaz, S.; Queiroz, E.F.; Conan, C.; Marcourt, L.; Wardojo, B.P.; Voinesco, F.; Buchwalder, A.; Gindro, K.; Sanglard, D.; et al. Comprehensive approach for the detection of antifungal compounds using a susceptible strain of Candida albicans and confirmation of in vivo activity with the Galleria mellonella model. Phytochemistry 2014, 105, 68-78. [CrossRef]

28. Nile, C.; Falleni, M.; Cirasola, D.; Alghamdi, A.; Anderson, O.F.; Delaney, C.; Ramage, G.; Ottaviano, E.; Tosi, D.; Bulfamante, G.; et al. Repurposing pilocarpine hydrochloride for treatment of Candida albicans infections. mSphere 2019, 4, e00689. [CrossRef]

29. Osmanov, A.; Wise, A.; Denning, D.W. In vitro and in vivo efficacy of miramistin against drug-resistant fungi. J. Med. Microbiol. 2019, 68, 1047-1052. [CrossRef]

30. Rossoni, R.D.; de Barros, P.P.; Lopes, L.; Ribeiro, F.C.; Nakatsuka, T.; Kasaba, H.; Junqueira, J.C. Effects of surface pre-reacted glass-ionomer (S-PRG) eluate on Candida spp.: Antifungal activity, anti-biofilm properties, and protective effects on Galleria mellonella against C. albicans infection. Biofouling 2019, 35, 997-1006. [CrossRef]

31. Rowan, R.; Moran, C.; McCann, M.; Kavanagh, K. Use of Galleria mellonella larvae to evaluate the in vivo anti-fungal activity of [Ag2(mal)(phen)3]. Biometals Int. J. Role Met. Ions Biol. Biochem. Med. 2009, 22, 461-467. [CrossRef] [PubMed]

32. Sa, N.P.; Lima, C.M.; JR, A.D.S.; Costa, M.C.; de Barros, P.P.; Junqueira, J.C.; Vaz, J.A.; Oliveira, R.B.; Fuchs, B.B.; Mylonakis, E.; et al. A phenylthiazole derivative demonstrates efficacy on treatment of the cryptococcosis \& candidiasis in animal models. Future Sci. Oa 2018, 4, dFso305. [CrossRef]

33. Spadari, C.C.; de Bastiani, F.; Lopes, L.B.; Ishida, K. Alginate nanoparticles as non-toxic delivery system for miltefosine in the treatment of candidiasis and cryptococcosis. Int. J. Nanomed. 2019, 14, 5187-5199. [CrossRef]

34. Staniszewska, M.; Gizinska, M.; Mikulak, E.; Adamus, K.; Koronkiewicz, M.; Lukowska-Chojnacka, E. New 1,5 and 2,5-disubstituted tetrazoles-dependent activity towards surface barrier of Candida albicans. Eur. J. Med. Chem. 2018, 145, 124-139. [CrossRef] [PubMed]

35. Cowen, L.E.; Singh, S.D.; Kohler, J.R.; Collins, C.; Zaas, A.K.; Schell, W.A.; Aziz, H.; Mylonakis, E.; Perfect, J.R.; Whitesell, L.; et al. Harnessing Hsp90 function as a powerful, broadly effective therapeutic strategy for fungal infectious disease. Proc. Natl. Acad. Sci. USA 2009, 106, 2818-2823. [CrossRef]

36. Gu, W.; Yu, Q.; Yu, C.; Sun, S. In vivo activity of fluconazole/tetracycline combinations in Galleria mellonella with resistant Candida albicans infection. J. Glob. Antimicrob. Resist. 2018, 13, 74-80. [CrossRef]

37. Li, X.; Wu, X.; Gao, Y.; Hao, L. Synergistic effects and mechanisms of combined treatment with harmine hydrochloride and azoles for resistant Candida albicans. Front. Microbiol. 2019, 10, 2295. [CrossRef]

38. Li, X.; Zhao, Y.; Huang, X.; Yu, C.; Yang, Y.; Sun, S. Ambroxol hydrochloride combined with fluconazole reverses the resistance of Candida albicans to fluconazole. Front. Cell Infect. Microbiol. 2017, 7, 124. [CrossRef]

39. Li, Y.; Jiao, P.; Li, Y.; Gong, Y.; Chen, X.; Sun, S. The synergistic antifungal effect and potential mechanism of D-penicillamine combined with fluconazole against Candida albicans. Front. Microbiol. 2019, 10, 2853. [CrossRef]

40. Liu, X.; Li, T.; Wang, D.; Yang, Y.; Sun, W.; Liu, J.; Sun, S. Synergistic antifungal effect of fluconazole combined with licofelone against resistant Candida albicans. Front. Microbiol. 2017, 8, 2101. [CrossRef]

41. Lu, M.; Yang, X.; Yu, C.; Gong, Y.; Yuan, L.; Hao, L.; Sun, S. Linezolid in combination with azoles induced synergistic effects against Candida albicans and protected Galleria mellonella against experimental candidiasis. Front. Microbiol. 2019, 9, 3142. [CrossRef] [PubMed]

42. Lu, M.; Yu, C.; Cui, X.; Shi, J.; Yuan, L.; Sun, S. Gentamicin synergises with azoles against drug-resistant Candida albicans. Int. J. Antimicrob. Agents 2018, 51, 107-114. [CrossRef] [PubMed] 
43. Sun, W.; Wang, D.; Yu, C.; Huang, X.; Li, X.; Sun, S. Strong synergism of dexamethasone in combination with fluconazole against resistant Candida albicans mediated by inhibiting drug efflux and reducing virulence. Int. J. Antimicrob. Agents 2017, 50, 399-405. [CrossRef] [PubMed]

44. Zhang, M.; Yan, H.; Lu, M.; Wang, D.; Sun, S. Antifungal activity of ribavirin used alone or in combination with fluconazole against Candida albicans is mediated by reduced virulence. Int. J. Antimicrob. Agents 2020, 55, 105804. [CrossRef]

45. de Castro Spadari, C.; da Silva de Bastiani, F.W.M.; Pisani, P.B.B.; de Azevedo Melo, A.S.; Ishida, K. Efficacy of voriconazole in vitro and in invertebrate model of cryptococcosiss. Arch. Microbiol. 2019. [CrossRef]

46. de Sa, N.P.; de Barros, P.P.; Junqueira, J.C.; Vaz, J.A.; de Oliveira, R.B.; Rosa, C.A.; Santos, D.A.; Johann, S. Thiazole derivatives act on virulence factors of Cryptococcus spp. Med. Mycol. 2019, 57, 84-91. [CrossRef]

47. Mylonakis, E.; Moreno, R.; El Khoury, J.B.; Idnurm, A.; Heitman, J.; Calderwood, S.B.; Ausubel, F.M.; Diener, A. Galleria mellonella as a model system to study Cryptococcus neoformans pathogenesis. Infect. Immun. 2005, 73, 3842-3850. [CrossRef]

48. Palanco, A.C.; Lacorte Singulani, J.; Costa-Orlandi, C.B.; Gullo, F.P.; Strohmayer Lourencetti, N.M.; Gomes, P.C.; Ayusso, G.M.; Dutra, L.A.; Silva Bolzani, V.D.; Regasini, L.O.; et al. Activity of 3'-hydroxychalcone against Cryptococcus gattii and toxicity, and efficacy in alternative animal models. Future Microbiol. 2017, 12, 1123-1134. [CrossRef]

49. Sangalli-Leite, F.; Scorzoni, L.; Alves de Paula e Silva, A.C.; da Silva, J.F.; de Oliveira, H.C.; de Lacorte Singulani, J.; Gullo, F.P.; Moraes da Silva, R.; Regasini, L.O.; Siqueira da Silva, D.H.; et al. Synergistic effect of pedalitin and amphotericin B against Cryptococcus neoformans by in vitro and in vivo evaluation. Int. J. Antimicrob. Agents 2016, 48, 504-511. [CrossRef]

50. Singulani, J.L.; Galeane, M.C.; Ramos, M.D.; Gomes, P.C.; Dos Santos, C.T.; de Souza, B.M.; Palma, M.S.; Fusco Almeida, A.M.; Mendes Giannini, M.J.S. Antifungal activity, toxicity, and membranolytic action of a mastoparan analog peptide. Front. Cell Infect. Microbiol. 2019, 9, 419. [CrossRef]

51. Vu, K.; Gelli, A. Astemizole and an analogue promote fungicidal activity of fluconazole against Cryptococcus neoformans var. grubii and Cryptococcus gattii. Med. Mycol. 2010, 48, 255-262. [CrossRef] [PubMed]

52. Blatzer, M.; Blum, G.; Jukic, E.; Posch, W.; Gruber, P.; Nagl, M.; Binder, U.; Maurer, E.; Sarg, B.; Lindner, H.; et al. Blocking Hsp70 enhances the efficiency of amphotericin B treatment against resistant Aspergillus terreus strains. Antimicrob. Agents Chemother. 2015, 59, 3778-3788. [CrossRef] [PubMed]

53. Forastiero, A.; Bernal-Martinez, L.; Mellado, E.; Cendejas, E.; Gomez-Lopez, A. In vivo efficacy of voriconazole and posaconazole therapy in a novel invertebrate model of Aspergillus fumigatus infection. Int. J. Antimicrob. Agents 2015, 46, 511-517. [CrossRef] [PubMed]

54. Garcia-Rubio, R.; Alcazar-Fuoli, L.; Monteiro, M.C.; Monzon, S.; Cuesta, I.; Pelaez, T.; Mellado, E. Insight into the significance of Aspergillus fumigatus cyp51A polymorphisms. Antimicrob. Agents Chemother. 2018, 62, e00241. [CrossRef]

55. Glampedakis, E.; Coste, A.T.; Aruanno, M.; Bachmann, D.; Delarze, E.; Erard, V.; Lamoth, F. Efficacy of antifungal monotherapies and combinations against Aspergillus calidoustus. Antimicrob. Agents Chemother. 2018, 62, e01137. [CrossRef]

56. Maurer, E.; Browne, N.; Surlis, C.; Jukic, E.; Moser, P.; Kavanagh, K.; Lass-Florl, C.; Binder, U. Galleria mellonella as a host model to study Aspergillus terreus virulence and amphotericin B resistance. Virulence 2015, 6, 591-598. [CrossRef]

57. Ben Yaakov, D.; Rivkin, A.; Mircus, G.; Albert, N.; Dietl, A.M.; Kovalerchick, D.; Carmeli, S.; Haas, H.; Kontoyiannis, D.P.; Osherov, N. Identification and characterization of haemofungin, a novel antifungal compound that inhibits the final step of haem biosynthesis. J. Antimicrob. Chemother. 2016, 71, 946-952. [CrossRef]

58. Ben Yaakov, D.; Shadkchan, Y.; Albert, N.; Kontoyiannis, D.P.; Osherov, N. The quinoline bromoquinol exhibits broad-spectrum antifungal activity and induces oxidative stress and apoptosis in Aspergillus fumigatus. J. Antimicrob. Chemother. 2017, 72, 2263-2272. [CrossRef]

59. Liu, F.F.; Pu, L.; Zheng, Q.Q.; Zhang, Y.W.; Gao, R.S.; Xu, X.S.; Zhang, S.Z.; Lu, L. Calcium signaling mediates antifungal activity of triazole drugs in the Aspergilli. Fungal Genet. Biol. 2015, 81, 182-190. [CrossRef]

60. Mircus, G.; Albert, N.; Ben-Yaakov, D.; Chikvashvili, D.; Shadkchan, Y.; Kontoyiannis, D.P.; Osherov, N. Identification and characterization of a novel family of selective antifungal compounds (CANBEFs) that interfere with fungal protein synthesis. Antimicrob. Agents Chemother. 2015, 59, 5631-5640. [CrossRef] 
61. Trevino-Rangel, R.J.; Villanueva-Lozano, H.; Mendez-Galomo, K.S.; Solis-Villegas, E.M.; Becerril-Garcia, M.A.; Montoya, A.M.; Robledo-Leal, E.R.; Gonzalez, G.M. In vivo evaluation of the antifungal activity of sertraline against Aspergillus fumigatus. J. Antimicrob. Chemother. 2019, 74, 663-666. [CrossRef] [PubMed]

62. Bastidas, R.J.; Shertz, C.A.; Lee, S.C.; Heitman, J.; Cardenas, M.E. Rapamycin exerts antifungal activity in vitro and in vivo against Mucor circinelloides via FKBP12-dependent inhibition of Tor. Eukaryot Cell 2012, 11, 270-281. [CrossRef] [PubMed]

63. Macedo, D.; Leonardelli, F.; Dudiuk, C.; Vitale, R.G.; Del Valle, E.; Giusiano, G.; Gamarra, S.; Garcia-Effron, G. In vitro and in vivo evaluation of voriconazole-containing antifungal combinations against Mucorales using a Galleria mellonella model of mucormycosis. J. Fungi (Basel) 2019, 5, 5. [CrossRef] [PubMed]

64. Maurer, E.; Hortnagl, C.; Lackner, M.; Grassle, D.; Naschberger, V.; Moser, P.; Segal, E.; Semis, M.; Lass-Florl, C.; Binder, U. Galleria mellonella as a model system to study virulence potential of mucormycetes and evaluation of antifungal treatment. Med. Mycol. 2019, 57, 351-362. [CrossRef] [PubMed]

65. Eadie, K.; Parel, F.; Helvert-van Poppel, M.; Fahal, A.; van de Sande, W. Combining two antifungal agents does not enhance survival of Galleria mellonella larvae infected with Madurella mycetomatis. Trop. Med. Int. Health 2017, 22, 696-702. [CrossRef] [PubMed]

66. Kloezen, W.; Parel, F.; Bruggemann, R.; Asouit, K.; Helvert-van Poppel, M.; Fahal, A.; Mouton, J.; van de Sande, W. Amphotericin B and terbinafine but not the azoles prolong survival in Galleria mellonella larvae infected with Madurella mycetomatis. Med. Mycol. 2018, 56, 469-478. [CrossRef]

67. Lim, W.; Melse, Y.; Konings, M.; Phat Duong, H.; Eadie, K.; Laleu, B.; Perry, B.; Todd, M.H.; Ioset, J.R.; van de Sande, W.W.J. Addressing the most neglected diseases through an open research model: The discovery of fenarimols as novel drug candidates for eumycetoma. Plos Negl. Trop. Dis. 2018, 12, e0006437. [CrossRef]

68. Marine, M.; Bom, V.L.; de Castro, P.A.; Winkelstroter, L.K.; Ramalho, L.N.; Brown, N.A.; Goldman, G.H. The development of animal infection models and antifungal efficacy assays against clinical isolates of Trichosporon asahii, T. asteroides and T. inkin. Virulence 2015, 6, 476-486. [CrossRef]

69. de Lacorte Singulani, J.; Scorzoni, L.; de Paula, E.S.A.C.; Fusco-Almeida, A.M.; Mendes-Giannini, M.J. Evaluation of the efficacy of antifungal drugs against Paracoccidioides brasiliensis and Paracoccidioides lutzii in a Galleria mellonella model. Int. J. Antimicrob. Agents 2016, 48, 292-297. [CrossRef]

70. Singulani, J.L.; Scorzoni, L.; de Oliveira, H.C.; Marcos, C.M.; Assato, P.A.; Fusco-Almeida, A.M.; Mendes-Giannini, M.J.S. Applications of invertebrate animal models to dimorphic fungal infections. J. Fungi (Basel) 2018, 4, 118. [CrossRef]

71. Jacobsen, I.D. Galleria mellonella as a model host to study virulence of Candida. Virulence 2014, 5, $237-239$. [CrossRef] [PubMed]

72. Segal, E.; Frenkel, M. Experimental in vivo models of candidiasis. J. Fungi (Basel) 2018, 4, 21. [CrossRef] [PubMed]

73. Lu, M.; Yan, H.; Yu, C.; Yuan, L.; Sun, S. Proton pump inhibitors act synergistically with fluconazole against resistant Candida albicans. Sci. Rep. 2020, 10, 498. [CrossRef] [PubMed]

74. Diekema, D.; Arbefeville, S.; Boyken, L.; Kroeger, J.; Pfaller, M. The changing epidemiology of healthcare-associated candidemia over three decades. Diagn. Microbiol. Infect. Dis. 2012, 73, 45-48. [CrossRef] [PubMed]

75. MacCallum, D.M.; Desbois, A.P.; Coote, P.J. Enhanced efficacy of synergistic combinations of antimicrobial peptides with caspofungin versus Candida albicans in insect and murine models of systemic infection. Eur. J. Clin. Microbiol. Infect. Dis. Off. Publ. Eur. Soc. Clin. Microbiol. 2013, 32, 1055-1062. [CrossRef] [PubMed]

76. Cornely, O.A.; Bassetti, M.; Calandra, T.; Garbino, J.; Kullberg, B.J.; Lortholary, O.; Meersseman, W.; Akova, M.; Arendrup, M.C.; Arikan-Akdagli, S.; et al. ESCMID* guideline for the diagnosis and management of Candida diseases 2012: Non-neutropenic adult patients. Clin. Microbiol. Infect. 2012, 18, 19-37. [CrossRef] [PubMed]

77. Bidaud, A.L.; Botterel, F.; Chowdhary, A.; Dannaoui, E. In vitro antifungal combination of flucytosine with amphotericin B, voriconazole, or micafungin against Candida auris shows no antagonism. Antimicrob. Agents Chemother. 2019. [CrossRef]

78. Bidaud, A.L.; Djenontin, E.; Botterel, F.; Chowdhary, A.; Dannaoui, E. Colistin interacts synergistically with echinocandins against Candida auris. Int. J. Antimicrob. Agents 2020. [CrossRef]

79. Apidianakis, Y.; Rahme, L.G.; Heitman, J.; Ausubel, F.M.; Calderwood, S.B.; Mylonakis, E. Challenge of Drosophila melanogaster with Cryptococcus neoformans and role of the innate immune response. Eukaryot Cell 2004, 3, 413-419. [CrossRef] 
80. Wang, Y.H.; Dong, H.H.; Zhao, F.; Wang, J.; Yan, F.; Jiang, Y.Y.; Jin, Y.S. The synthesis and synergistic antifungal effects of chalcones against drug resistant Candida albicans. Bioorg. Med. Chem. Lett. 2016, 26, 3098-3102. [CrossRef]

81. de Almeida Junior, J.N.; Hennequin, C. Invasive Trichosporon infection: A systematic review on a re-emerging fungal pathogen. Front. Microbiol. 2016, 7, 1629. [CrossRef] [PubMed]

82. Arendrup, M.C.; Boekhout, T.; Akova, M.; Meis, J.F.; Cornely, O.A.; Lortholary, O.; Escmid Efisg study group; Ecmm. ESCMID and ECMM joint clinical guidelines for the diagnosis and management of rare invasive yeast infections. Clin. Microbiol. Infect. 2014, 20, 76-98. [CrossRef] [PubMed]

83. Alcazar-Fuoli, L.; Buitrago, M.; Gomez-Lopez, A.; Mellado, E. An alternative host model of a mixed fungal infection by azole susceptible and resistant Aspergillus spp strains. Virulence 2015, 6, 376-384. [CrossRef] [PubMed]

84. Mellado, E.; Alcazar-Fuoli, L.; Cuenca-Estrella, M.; Rodriguez-Tudela, J.L. Role of Aspergillus lentulus 14-alpha sterol demethylase (Cyp51A) in azole drug susceptibility. Antimicrob. Agents Chemother. 2011, 55, 5459-5468. [CrossRef]

85. Lestrade, P.P.A.; Meis, J.F.; Melchers, W.J.G.; Verweij, P.E. Triazole resistance in Aspergillus fumigatus: Recent insights and challenges for patient management. Clin. Microbiol. Infect. 2019, 25, 799-806. [CrossRef]

86. Rhein, J.; Morawski, B.M.; Hullsiek, K.H.; Nabeta, H.W.; Kiggundu, R.; Tugume, L.; Musubire, A.; Akampurira, A.; Smith, K.D.; Alhadab, A.; et al. Efficacy of adjunctive sertraline for the treatment of HIV-associated cryptococcal meningitis: An open-label dose-ranging study. Lancet Infect. Dis. 2016, 16, 809-818. [CrossRef]

87. Cornely, O.A.; Alastruey-Izquierdo, A.; Arenz, D.; Chen, S.C.A.; Dannaoui, E.; Hochhegger, B.; Hoenigl, M.; Jensen, H.E.; Lagrou, K.; Lewis, R.E.; et al. Global guideline for the diagnosis and management of mucormycosis: An initiative of the European Confederation of Medical Mycology in cooperation with the Mycoses Study Group Education and Research Consortium. Lancet Infect. Dis. 2019, 19, e405-e421. [CrossRef]

88. Prakash, H.; Chakrabarti, A. Global epidemiology of mucormycosis. J. Fungi (Basel) 2019, 5, 26. [CrossRef]

89. Serris, A.; Danion, F.; Lanternier, F. Disease Entities in Mucormycosis. J. Fungi (Basel) 2019, 5, 23. [CrossRef]

90. Bitar, D.; Van Cauteren, D.; Lanternier, F.; Dannaoui, E.; Che, D.; Dromer, F.; Desenclos, J.C.; Lortholary, O. Increasing incidence of zygomycosis (mucormycosis), France, 1997-2006. Emerg Infect. Dis. 2009, 15, 1395-1401. [CrossRef]

91. Kaerger, K.; Schwartze, V.U.; Dolatabadi, S.; Nyilasi, I.; Kovacs, S.A.; Binder, U.; Papp, T.; Hoog, S.; Jacobsen, I.D.; Voigt, K. Adaptation to thermotolerance in Rhizopus coincides with virulence as revealed by avian and invertebrate infection models, phylogeny, physiological and metabolic flexibility. Virulence 2015, 6, 395-403. [CrossRef] [PubMed]

92. Semis, R.; Mendlovic, S.; Polacheck, I.; Segal, E. Activity of an intralipid formulation of nystatin in murine systemic candidiasis. Int. J. Antimicrob. Agents 2011, 38, 336-340. [CrossRef] [PubMed]

93. Grizanova, E.V.; Krytsyna, T.I.; Surcova, V.S.; Dubovskiy, I.M. The role of midgut nonspecific esterase in the susceptibility of Galleria mellonella larvae to Bacillus thuringiensis. J. Invertebr. Pathol. 2019, 166, 107208. [CrossRef] [PubMed]

94. Kloezen, W.; van Helvert-van Poppel, M.; Fahal, A.H.; van de Sande, W.W. A Madurella mycetomatis grain model in Galleria mellonella larvae. PLoS Negl. Trop. Dis. 2015, 9, e0003926. [CrossRef]

95. Astvad, K.M.T.; Meletiadis, J.; Whalley, S.; Arendrup, M.C. Fluconazole pharmacokinetics in Galleria mellonella larvae and performance evaluation of a bioassay compared to liquid chromatography-tandem mass spectrometry for hemolymph specimens. Antimicrob. Agents Chemother. 2017, 61, e00895. [CrossRef]

(C) 2020 by the authors. Licensee MDPI, Basel, Switzerland. This article is an open access article distributed under the terms and conditions of the Creative Commons Attribution (CC BY) license (http://creativecommons.org/licenses/by/4.0/). 